\title{
Radiological study of pleural changes in relation to mesothelioma in Turkey
}

\author{
GUNNAR HILLERDAL, YI BARIS \\ From the Department of Lung Medicine, University Hospital, Uppsala, Sweden, and the Department of Chest \\ Medicine, Hacettepe University, Ankara, Turkey
}

ABSTRACT In some villages in central Turkey pleural changes occur as a result of environmental exposure to mineral fibres. In most cases the fibre is asbestos but in some cases the non-asbestos fibre erionite, a zeolite, is responsible. The incidence of malignant mesothelioma is much higher in "erionite villages" than in "asbestos villages" despite similar frequencies of pleural changes. In this study chest radiographs from 466 people from asbestos villages, 549 from erionite villages, and 382 controls were compared. The frequency of pleural calcification was about the same in the two groups of villages studied, but the minor fissures were visible to a greater degree in erionite cases. In people from erionite villages "atypical" pleural calcification, due to calcification of the visceral rather than the parietal pleura, was more common. These differences may indicate that the fibres have different lengths and diameters.

There are rural areas in many countries where pleural changes are endemic. ${ }^{1-11}$ In most of these areas the changes take the form of discrete plaques which calcify with increasing age. The typical appearance, shown in fig 1 , is not usually associated with noticeable loss of lung function or with an increased risk of malignancy; but in some areas of Turkey and South Africa there is an association between pleural changes in the general population and an increased incidence of malignancy, both mesothelioma and bronchial carcinoma.

At least two different mineral fibres are responsible for the endemic plaques in Turkey-namely, asbestos (in most affected villages) and the nonasbestos mineral erionite. ${ }^{812}$ In the "asbestos villages" there is only a moderate increase in malignancies, but in the "erionite villages" the incidence of mesotheliomas is extremely high. The objectives of the study we describe here were to describe the pleural changes in certain areas of Turkey and to determine whether they showed any difference in pattern between the areas where the incidence of malignancies was normal or only moderately increased and areas where it was high.

Address for reprint requests: Dr G Hillerdal, Department of Lung Medicine, University Hospital, S-751 85 Uppsala, Sweden.

Accepted 26 January 1983

\section{Methods}

Chest radiographs obtained in earlier field studies by the Hacettepe University investigation team from asbestos villages, erionite villages, and some control villages were restudied. All the villages are in central Anatolia (fig 2). The radiographs were obtained from a randomised sample from the adult population of the villages. Age and sex distribution were similar in all villages.

All the films showing no pleural change had been withdrawn from those obtained from the inhabitants of Mihaliccik (one of the asbestos villages). About a dozen films had been withdrawn from the other sets of films because they were needed for the clinical care of individuals. In all, there were 549 radiogxaphs from erionite villages (Sarihidir and Tuzköy), 466 from asbestos villages (Gürpinar, Maden, Mihaliccik, and Sarihaya), and 382 from villages without pleural disease as controls.

Only posteroanterior films were available and, because of difficulties in some localities, the quality was varied. Hence plaques were recorded only when they were calcified. Diffuse pleural thickening of the parietal pleura, costophrenic angles and interlobar fissures were recorded whether calcified or not. Pleural calcification was noted whenever there were typical pleural plaques - that is, discrete lesions with well-defined edges, as in figure 1 , or when there was pleural thickening with calcification, as in figs 3-5. 


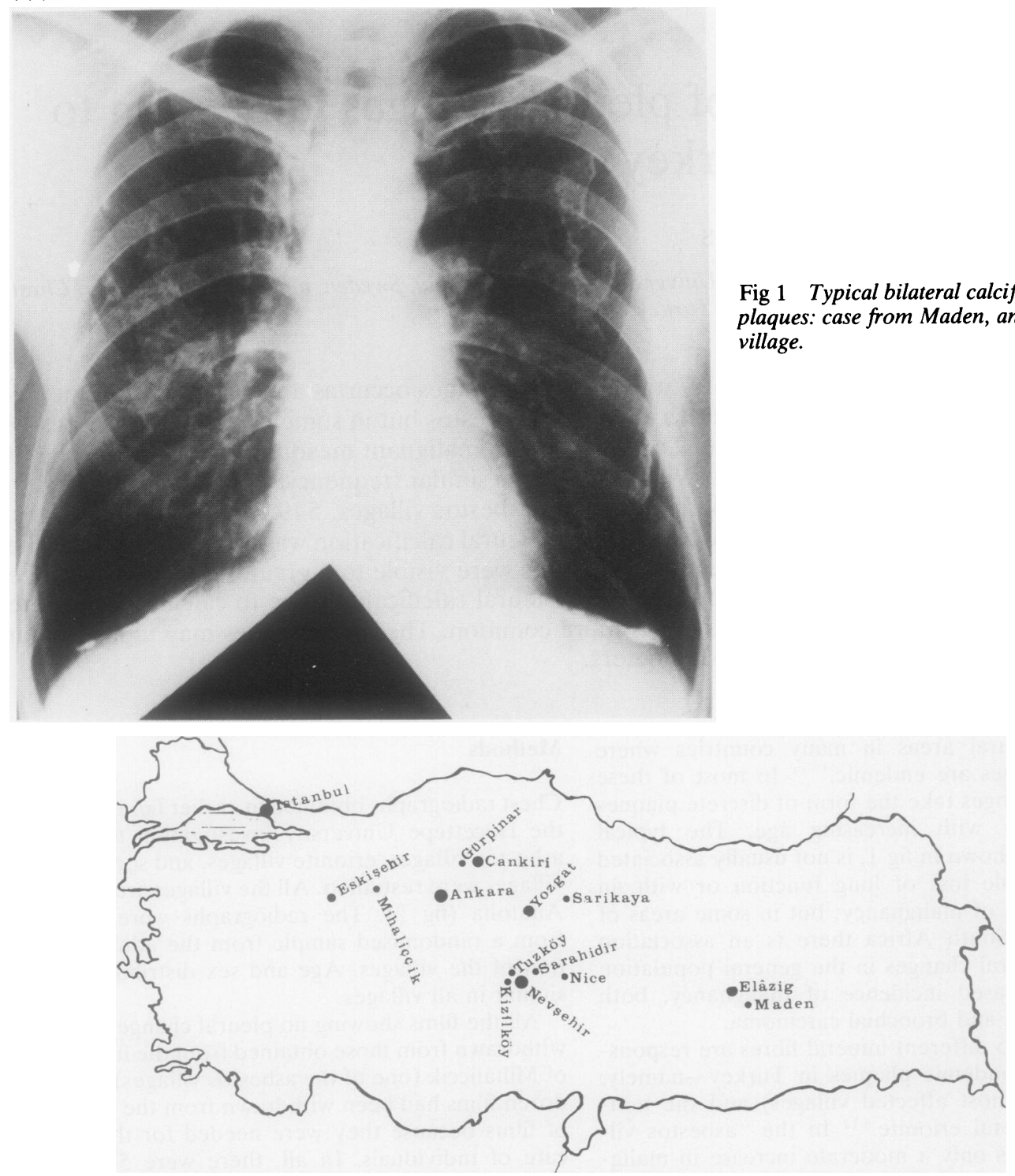

Fig 2 Map of Turkey with the villages investigated and their province capitals. Asbestos villages: Gürpinar, Maden, Mihaccilik, and Sarihaya; erionite villages: Sarihidir and Tuzköy; control villages: Nice and Kizilköy.

\section{Results}

The overall frequency of pleural changes in the three types of village is shown in table 1 . Pleural calcification was found in $22.3 \%$ of adults from asbestos villages and $14.2 \%$ of adults from the erionite villages compared with less than $1 \%$ of adults from the control villages. In those without calcification of the pleura apparent thickening of the pleura was seen in the minor fissure more frequentlyo in the erionite-exposed villagers $(26 \%)$ than in theo asbestos-exposed villagers $(15.7 \%)(p<0.001)$. Bilateral loss of the costophrenic angle was not seen?? in the controls and was most common in the villagers exposed to erionite.

Among persons with calcified pleura those from the erionite villages displayed rounded costophrenico angles and visible minor fissures more often thano 


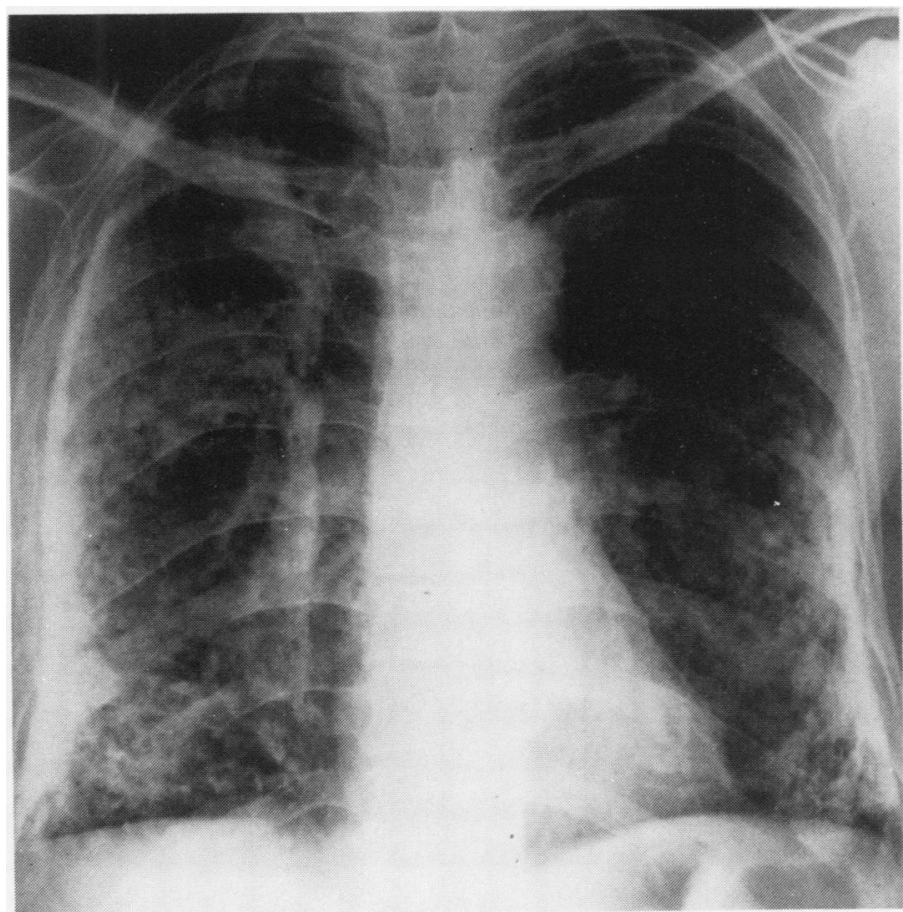

Fig 3 Bilateral extensive pleural calcification of the "atypical" type with a free zone between the ribs and the calcification: case from Sarihidir, an erionite village.

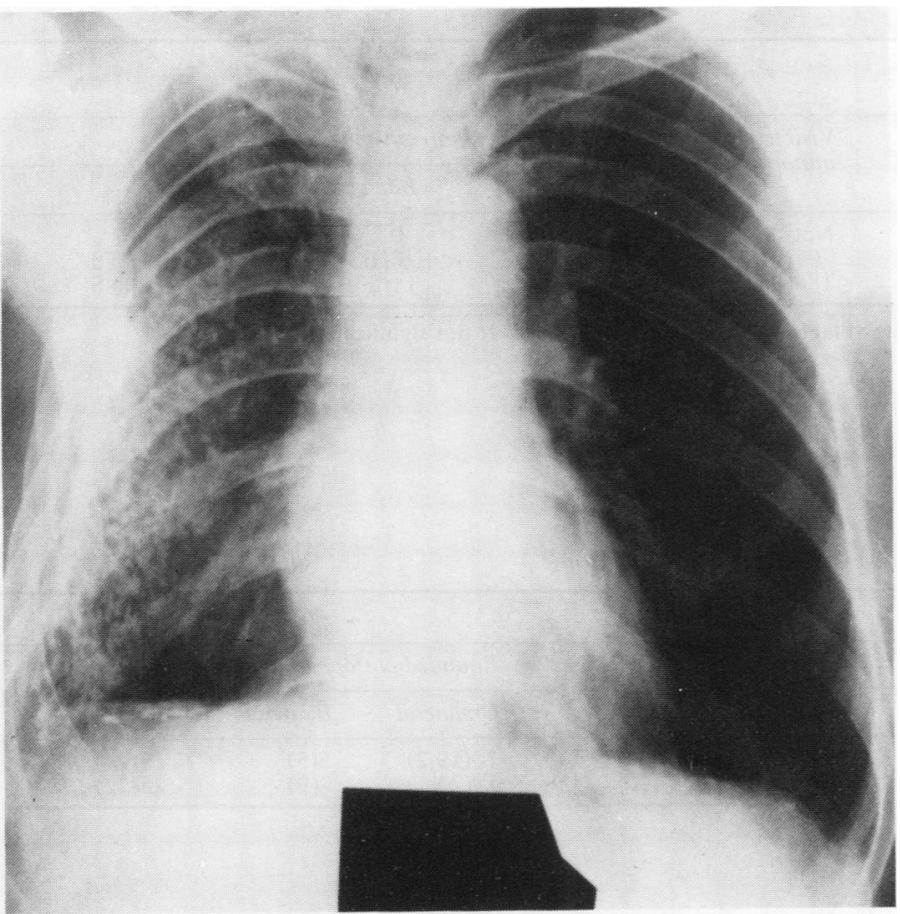

Fig 4 Right-sided "atypical"

calcification with free zone and on the left calcified plaques on the diaphragm: case from Maden, an asbestos village. 


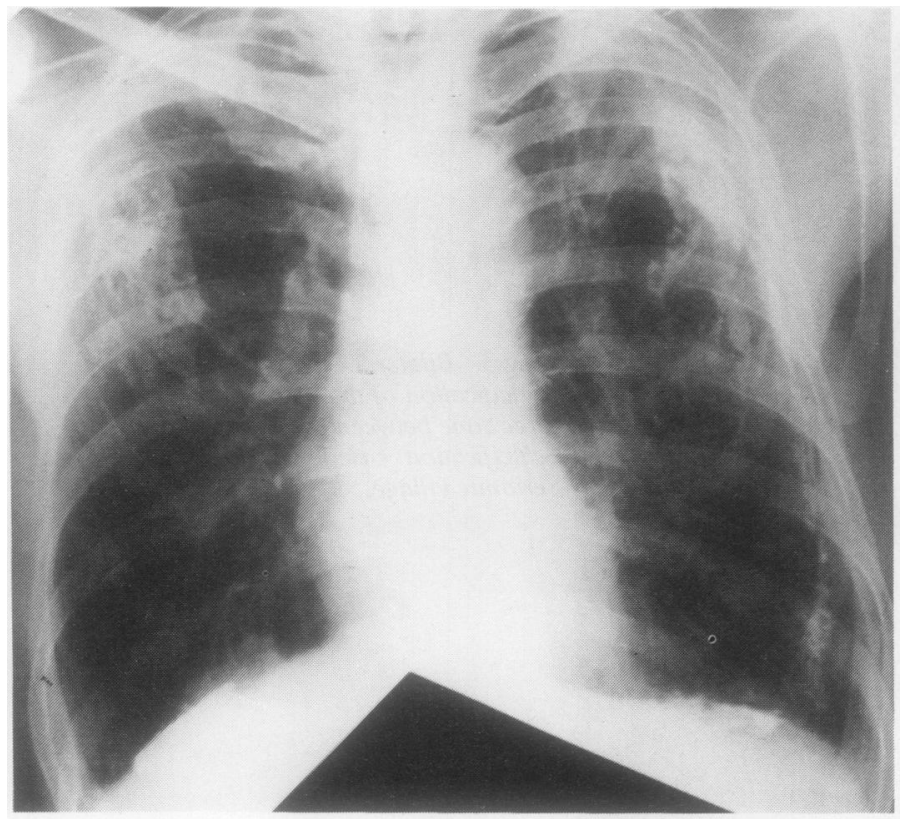

Fig 5 Bilateral diaphragmatic and apical calcification with a free zone at least on the left side apically: case from Maden, an asbestos village.

Table 1 Summary of radiological changes

\begin{tabular}{|c|c|c|c|c|c|c|}
\hline & \multicolumn{6}{|c|}{ No $(\%)$ of radiographs } \\
\hline & \multirow[t]{2}{*}{ Total } & \multirow{2}{*}{$\begin{array}{l}\text { Pleural } \\
\text { calcification }\end{array}$} & \multirow{2}{*}{$\begin{array}{l}\text { Visible } \\
\text { minor fissure }\end{array}$} & \multicolumn{3}{|c|}{ Obscured costophrenic angle } \\
\hline & & & & Unilateral & Bilateral & Total \\
\hline $\begin{array}{l}\text { Control villages } \\
\text { Asbestos villages } \\
\text { Erionite villages }\end{array}$ & $\begin{array}{l}382 \\
466 \\
549\end{array}$ & $\begin{array}{c}3(0 \cdot 8) \\
104(22 \cdot 3) \\
78(14 \cdot 2)\end{array}$ & $\begin{array}{l}\text { Not studied } \\
99(21 \cdot 2)^{* * *} \\
188(34 \cdot 2)^{* * *}\end{array}$ & $\begin{array}{r}6(1 \cdot 6) \\
30(6 \cdot 4) \\
42(7 \cdot 7)\end{array}$ & $\begin{array}{l}0 \\
6(1 \cdot 3) \\
11(2 \cdot 0)\end{array}$ & $\begin{array}{l}6(1 \cdot 6) \\
36(7 \cdot 7) \text { NS } \\
53(9 \cdot 7) \text { NS }\end{array}$ \\
\hline
\end{tabular}

${ }^{* * *}$ Significant difference between asbestos and erionite villages $(\mathrm{p}<0.001)$. NS-difference not significant.

Table 2 Additional radiological features in those with pleural calcification

\begin{tabular}{|c|c|c|c|c|c|c|c|c|}
\hline & \multicolumn{7}{|c|}{ No $(\%)$ of radiographs } & ర \\
\hline & \multirow{2}{*}{$\begin{array}{l}\text { Pleural } \\
\text { calcification }\end{array}$} & \multicolumn{3}{|c|}{ Visible minor fissure } & \multicolumn{3}{|c|}{ Rounded costophrenic angle } & $c$ \\
\hline & & Enlarged & Calcified & Total & Unilateral & Bilateral & Total & \\
\hline $\begin{array}{l}\text { Asbestos villages } \\
\text { Erionite villages }\end{array}$ & $\begin{array}{r}104 \\
78\end{array}$ & $\begin{array}{l}2 \\
4\end{array}$ & $\begin{array}{l}0 \\
5\end{array}$ & $\begin{array}{l}44(42) \\
45(57 \cdot 7)\end{array}$ & $\begin{array}{l}20(19 \cdot 2) \\
18(23 \cdot 1)\end{array}$ & $\begin{array}{l}5(5) \\
7(9)\end{array}$ & $\begin{array}{l}25(24) \\
25(32)\end{array}$ & $\frac{7}{0}$ \\
\hline
\end{tabular}


those from the asbestos villages, although this difference was not significant (table 2). The minor fissure was more often enlarged or calcified, or both, among those exposed to erionite than among those exposed to asbestos.

The most extensive type of pleural change found in this study is shown in figs 3 and 4 . This consists of diffuse thickening of the pleura on one or both sides to a thickness of about $1 \mathrm{~cm}$. It is usually associated with loss of the costophrenic angle. The calcification is granular and affects the pulmonary surface, leaving the bulk of the thickening and the parietal pleura uncalcified. This "atypical" change was found in 8 of the 10 cases of diffuse pleural thickening from the erionite villages, three of which were bilateral (fig 3 ). Only three cases of this type were seen among the 15 cases of diffuse pleural thickening from the asbestos villages and they were all unilateral.

The prevalence of discrete pleural plaques (that is, excluding the atypical cases) was the same in erionite and asbestos villages.

\section{Discussion}

The people whose radiographs were analysed for this study came from three types of village in the uplands of central Turkey known as Anatolia.

In the control villages there was no occupational or environmental exposure to asbestos or other fibrous minerals. The villagers showed little pleural disease and mesothelioma is believed to be nonexistent.

In the asbestos villages the soil and rocks in the areas yield various types of asbestos (chrysotile and amphiboles). Near some of these villages asbestos is mined for local use or for export on a small scale. Most of the exposure is to the amphibole tremolite, which is not suitable for normal commerical use because the fibres are too short. It is used locally for making baby powder and whitewashing the houses. In many of these villages calcified pleural plaques are common, affecting up to $25 \%$ of the adult population. Only in some of these villages has a raised incidence of mesothelioma been reported-the same villages in which the atypical changes described above are found. ${ }^{8}$ By contrast, in the other European countries where endemic plaques have been found only the typical discrete plaques have been described. In Finland they are related to anthophyllite asbestos, ${ }^{12}$ in Bulgaria to a mixture of anthophyllite and tremolite ${ }^{5}$ and in Austria to tremolite. ${ }^{7}$ There are also areas in which similar endemic plaques are found in Czechoslovakia, ${ }^{34}$ Russia, ${ }^{6}$ and Greece ${ }^{10}$; but here the fibre responsible has not yet been identified. In none of these European areas have the typical plaques been associated with a raised incidence of mesothelioma.

In the erionite villages-which include Karain, described previously ${ }^{13}$ - the fibre concentrations appear to be low; but exposure to erionite starts in infancy and gives rise to an exceedingly high incidence of mesothelioma. In Karain the incidence is 10000 times and in Tuzköy 650 times greater than that expected. Although the villages lie within $100 \mathrm{~km}$ of each other they are separated by many unaffected villages. The whole area lies on a thick layer of volcanic tuff partially converted into zeolites. The rock is widely used for building. The farming and building practices in the area appear to be the same and there is no asbestos to explain the differences in pleural diseases. There are, however, patchy areas of the volcanic tuff where the zeolites are fibrous. Much of this fibrous material is too coarse to be respirable but in the affected villages there is a fine fibrous component, erionite, which forms respirable dust. Erionite fibres have been found in the lungs of patients from these villages dying from mesothelioma ${ }^{14}$ and they can cause mesotheliomas in experimental animals. ${ }^{15}$

The pattern of pleural change in the erionite villages shows a high proportion of atypical changes. The association between this type of change and mesothelioma is seen in the asbestos villages and to an even greater extent in the erionite villages. Loss of the costophrenic angle might be an early indication of this change, which is probably only another variant of benign pleural reactions other than plaque formation that can be caused by mineral fibres. ${ }^{16}$ The thickening and calcification of the minor fissure is also an indication that the visceral pleura is affected and has been described from South Africa. ${ }^{17}$ Atypical pleural calcification, very similar to that seen in fig 1 , can also be seen in radiographs in papers from South Africa, though their atypical nature has not been emphasised. Only in South Africa and Turkey has an association between endemic pleural changes and mesothelioma been described.

The differences between the various areas in which endemic pleural changes are found can probably be explained by differences in the length and diameter of the various fibres responsible. This hypothesis needs to be tested by further epidemiological and mineralogical research.

We wish to express our sincere thanks to Dr Peter Elmes for his invaluable advice and the Anna Cederberg Foundation for financial support.

\section{References}

${ }^{1}$ Kiviluoto $\mathrm{R}$. Pleural calcification as a roentgenologic 
sign of non-occupational endemic anthophylliteasbestosis. Acta Radiol 1960;suppl 194:1-32.

${ }^{2}$ Raunio V. Occurrence of unusual pleural calcification in Finland. Studies on atmospheric pollution caused by asbestos. Ann Med Intern Fenniae 1966:55:47:1-20.

${ }^{3}$ Marsova D. Beitrag zur Ätiologie der Pleuraverkalkungen. Zschr Tbk 1964;121:329-34.

${ }^{4}$ Rous V, Studeny J. Aetiology of pleural plaques. Thorax 1970;25:270-84.

${ }^{5}$ Burilkov T, Babadjov L. Ein Beitrag zum endemischen Auftreten doppelseitiger Pleuraverkalkungen. Prax Pneumol 1970;24:433-8.

${ }^{6}$ Ginzburg EA, Silova MA, et al. Röntgenbild der nichtberufsbedingten Asbestose der Pleura. Radiol Diagn 1973;14:307-12.

${ }^{7}$ Neuberger M, Gründorfer W, Haider $\mathrm{M}$, et al. Umweltbedingte endemische Pleuraplaques. $\mathrm{Zbl} \mathrm{Bakt}$ Hyg 1978;167:391-404.

${ }^{8}$ Baris Y, Artvinli M, Sahin AA. Environmental mesothelioma in Turkey. Ann NY Acad Sci 1979;330:423-32.

${ }^{9}$ Yazicioglu S, Ilçayto R, Balci K, Şayli S, Yorulmaz B. Pleural calcification, pleural mesotheliomas, and bronchial cancers caused by tremolite dust. Thorax 1980;35:564-9.

${ }^{10}$ Bazas T, Bazas B, Kitas D, Gilson JC, McDonald JC.
Pleural calcification in North-west Greece. Lancet $\stackrel{?}{?}$ $1981 ;$ ii: 254.

"Sluis-Cremer GK, Du Toit RSJ. Asbestos-related心 radiological changes in residents of South Africano amphibole asbestos mining fields and the fibre counts $\frac{\sigma}{\sigma}$ to which they may have been exposed. IARC Sci Publ 1980;30:559-63.

12 Baris YI, Sahin AA, Ozesmi M, et al. An outbreak of pleural mesothelioma and chronic fibrosing pleurisy in the village of Karain/Ürgüp in Anatolia. Thorax 1978:33:181-92.

${ }^{13}$ Baris YI, Simonato L, Artvinli M, Saracci R, Skidmore JW. Malignant mesothelioma and radiological abnor- $\vec{\omega}$ malities in two villages in Central Turkey. Lancet $1981 ; \mathrm{i}: 984-7$.

${ }^{14}$ Sébastien P, Gandichet A, Bignon J, Baris YI. Zeolite bodies in human lungs from Turkey. Lab Invest $1981 ; 44: 420-5$.

${ }^{15}$ Suzuki Y, Rohl AN, Langer AM, Selikoff IJ. Meso- $\frac{\vec{A}}{\vec{A}}$ thelioma following intraperitoneal administration of $\omega$ zeolite. Fed Proc 1980;39:640.

${ }^{16}$ Hillerdal G. Non-malignant asbestos pleural disease Thorax 1981;36:669-75.

${ }^{17}$ Solomon A, Sluis-Cremer GK, Goldstein B. Visceral pleural plaque formation in asbestosis. Envir Res 1979;19:258-64. 